\title{
Methylenetetrahydrofolate Reductase (MTHFR) Gene rs1801133 C>T Polymorphisms and Lung Cancer Susceptibility: An Updated Meta-analysis
}

https://doi.org/10.1515/pteridines-2019-0008

received December 28, 2018; accepted March 19, 2019.

Abstract: Objective: The aim of this study was to investigate the methylenetetrahydrofolate reductase (MTHFR) gene rs1801133 C>T polymorphisms and lung cancer susceptibility by pooling openly published data.

Methods: Electronic databases of Medline, Web of Science, Embase, Google scholar, CBM and CNKI were systematic searched to find the relevant studies related to MTHFR gene rs1801133 $\mathrm{C}>\mathrm{T}$ polymorphisms and lung cancer susceptibility. The odds of TT, CT and CC alleles in lung cancer patients compared with healthy controls was pooled by the effect size of odds ratio (OR) and corresponding 95\% confidence interval $(95 \% \mathrm{CI})$ under random or fixed effect model. Publication bias was analyzed by Begg's funnel plot and Egger's line regression test.

Results: Overall, twenty-one studies relevant to MTHFR gene rs1801133 C>T polymorphisms and lung cancer susceptibility were included. The pooled data showed subject with $\mathrm{T}$ allele had significant increased risk of developing lung cancer in dominant $(\mathrm{OR}=1.14$, $95 \% \mathrm{CI}: 1.01-1.28, \mathrm{p}<0.05)$, recessive (OR=1.26, 95\%CI:1.081.48, $\mathrm{p}<0.01)$ and homologous (OR=1.36, 95\%CI:1.12-1.65, $\mathrm{p}<0.01)$ genetic model. Begg's funnel plot and Egger's line regression test showed significant publication bias in all genetic models.

Conclusion: Based on present data, subjects with TT or CT alleles may have increased susceptibility to lung cancer. However, due to significant publication bias, the conclusion should be drawn with caution and should be proved by further well-designed case-control or cohort studies relevant to MTHFR gene rs1801133 C >T polymorphisms and lung cancer risk.

\footnotetext{
*Corresponding author: Xiaoling Lu, Department of Respiratory, Zhejiang Hospital, China 310013, E-mail: leim4283@163.com Fang Liu, Guangyue Qin, Tingyu Tang, Qingdong Huang, Zhijun Li, He Huang: Department of Respiratory, Zhejiang Hospital, China 310013
}

Keywords: Lung cancer; MTHFR; polymorphisms; susceptibility; meta-analysis

\section{Introduction}

Global cancer statistical analysis has found that lung cancer, including non-small cell lung cancer (NSCLC) and small-cell lung cancer (SCLC), was the leading cause of malignant carcinoma related death in males and females worldwide in 2016 [1]. In females, the incidence of lung cancer is second only to breast cancer but is the first in males [2-4]. Cigarette smoking was confirmed as theleading cause of carcinogenesis in lung cancer patients. However, genetic factors including oncogenes, tumor suppressor genes and metabolic enzyme gene polymorphisms also play an important role in the development of lung cancer.

Methylenetetrahydrofolatereductaseisakeyenzymein the folate metabolism pathway coded by MTHFR gene [5, 6] Methylenetetrahydrofolate reductase irreversibly converts folic acid metabolite 5, 10-methylenetetrahydrofolic acid to 5-methyltetrahydrofolic acid and further provides the materials for DNA synthesis. MTHFR rs1801133 C>T is one the most common polymorphism SNP sites which cause alanine to be replaced with valine and reduces enzyme activity and heat resistance. Correlations between MTHFR gene rs1801133 C>T polymorphisms and cancer susceptibility has been widely discussed in lung cancer $[7,8]$, esophageal cancer $[9,10]$, colorectal cancer [11, 12], breast cancer [13], and other cancers. MTHFR gene rs1801133 C $>\mathrm{T}$ polymorphisms and lung cancer risk was evaluated by several case-control studies with inconclusive results $[7,8]$. Therefore, we performed this updated meta-analysis. 


\section{Material and Methods}

\section{Search strategy}

Electronic databases of Medline, Web of Science, Embase, Google scholar, CBM and CNKI were systematic searched to find the relevant studies related to MTHFR gene rs1801133 C>T polymorphisms and lung cancer susceptibility. The publication identification process was performed according to the Cochrane handbook and demonstrated by Figure 1. The terms "lung cancer OR carcinoma of the lung OR non-small cell lung cancer OR NSCLC” AND "methylenetetrahydrofolate reductase OR MTHFR", were used to identify relevant studies.

\section{Study selection criteria}

The inclusion criteria used to screen all identified articles were: (1) lung cancer, including non-small cell lung cancer and small cell lung cancer, was confirmed by pathology or clinical diagnosis; (2) the controls were healthy subjects without any malignant diseases; (3) the genotype of the lung cancer and controls could be extracted from original studies; (4) the study type was either a case-control study or a cohort study; (5) the studies were published in English or Chinese.

\section{Data extraction and critical appraisal}

Two reviewers carefully read the included full-text papers and extracted the eligible information and data independently according to the Cochrane Handbook. The extracted information and data included: (1) first and corresponding authors; (2) year of publication; (3) region of the work performed; (4) ethnicity of the included subjects; (5) control type (hospital-based or population-based); (6) Hardy-Weinberg equilibrium (HWE) of the control group; (7) TT, CT and CC allele frequency in original study of the case and control groups.

\section{Statistical analysis}

The odds of TT, CT and CC alleles in lung cancer patients compared with healthy controls were pooled by the effect size of odds ratio (OR) and corresponding 95\% confidence interval $(95 \% \mathrm{CI})$ under random or fixed effect model. The statistical heterogeneity of the included publications in each genetic model was assessed by $\mathrm{I}^{2}$ test. The $\mathrm{OR}$

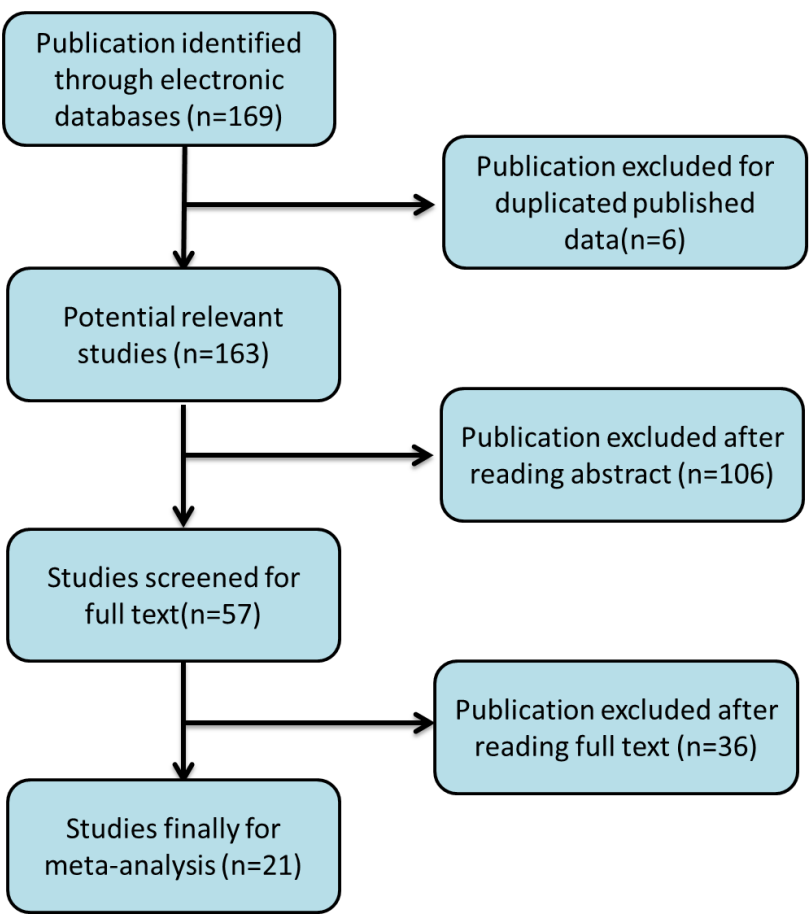

Figure 1: The study search strategy.

was pooled by random or fixed effect model according to statistical heterogeneity. The publication bias was evaluated by Begg's funnel plot and Egger's line regression test[14]. All the data analysis was performed using STATA/SE 11.0 software (http://www.stata.com; Stata Corporation, College Station, TX). A two-tailed p-value less than 0.05 was considered statistically significant.

\section{Results}

\section{General characteristics of the included publications}

After systematically searching the electronic databases, a total of 21 studies were included in the present metaanalysis. The main characteristics of the studies were shown in Table 1.

\section{Statistical heterogeneity analysis}

The statistical heterogeneity of the effect size in each different genetic model was assessed by $\mathrm{I}^{2}$ test. Significant statistical heterogeneity was found in the dominant, recessive and homologous genetic models (Table 2). 
Table 1: General information of the included original publications.

\begin{tabular}{|c|c|c|c|c|c|c|c|c|c|c|c|c|c|}
\hline \multirow[t]{2}{*}{ First author } & \multirow[t]{2}{*}{ Year } & \multirow[t]{2}{*}{ Region } & \multirow[t]{2}{*}{ Control type } & \multicolumn{3}{|c|}{ Case } & \multirow[b]{2}{*}{ CC } & \multirow[b]{2}{*}{$n$} & \multicolumn{2}{|c|}{ Control } & \multirow[b]{2}{*}{ CC } & \multirow[t]{2}{*}{ HWE } & \multirow[t]{2}{*}{ Race } \\
\hline & & & & $\bar{n}$ & TT & $\mathrm{CT}$ & & & TT & CT & & & \\
\hline Sun[15] & 2018 & China & Population-based & 225 & 52 & 113 & 60 & 225 & 24 & 124 & 77 & Yes & East Asia \\
\hline Cai[16] & 2014 & China & Population-based & 202 & 46 & 102 & 54 & 202 & 21 & 112 & 69 & Yes & East Asia \\
\hline $\mathrm{Ma}[17]$ & 2012 & China & Hospital-based & 120 & 46 & 54 & 20 & 60 & 10 & 28 & 22 & Yes & East Asia \\
\hline Cheng[18] & 2011 & China & Hospital-based & 178 & 71 & 58 & 49 & 180 & 45 & 88 & 47 & Yes & East Asia \\
\hline Cui[8] & 2011 & China & Hospital-based & 438 & 140 & 240 & 58 & 641 & 195 & 325 & 121 & Yes & East Asia \\
\hline Arslan[19] & 2011 & Turkey & Population-based & 64 & 7 & 27 & 30 & 61 & 3 & 29 & 29 & Yes & Caucasians \\
\hline Cui[7] & 2011 & Korea & Hospital-based & 3938 & 668 & 1909 & 1361 & 1700 & 298 & 862 & 540 & Yes & East Asia \\
\hline Yao[20] & 2010 & China & Hospital-based & 93 & 20 & 46 & 27 & 106 & 19 & 51 & 36 & Yes & East Asia \\
\hline Yang[21] & 2010 & China & Hospital-based & 120 & 19 & 52 & 49 & 165 & 28 & 75 & 62 & Yes & East Asia \\
\hline Liu[22] & 2009 & Taiwan & Population-based & 358 & 29 & 124 & 205 & 716 & 63 & 291 & 362 & Yes & East Asia \\
\hline Liu[23] & 2008 & China & Hospital-based & 500 & 98 & 245 & 157 & 517 & 103 & 265 & 149 & Yes & East Asia \\
\hline $\operatorname{Jin}[24]$ & 2007 & China & Population-based & 100 & 24 & 52 & 24 & 100 & 13 & 48 & 39 & Yes & East Asia \\
\hline Huang[25] & 2007 & France & Hospital-based & 2169 & 231 & 929 & 1009 & 2803 & 259 & 1147 & 1397 & Yes & Caucasians \\
\hline Suzuki[26] & 2007 & Japan & Hospital-based & 515 & 77 & 256 & 182 & 1048 & 177 & 474 & 397 & Yes & East Asia \\
\hline Shi[27] & 2005 & US & Population-based & 1051 & 100 & 468 & 483 & 1141 & 124 & 519 & 498 & Yes & Mixed \\
\hline Zhang[28] & 2005 & China & Population-based & 505 & 155 & 230 & 120 & 500 & 109 & 231 & 160 & Yes & East Asia \\
\hline Shen[29] & 2005 & China & Hospital-based & 116 & 18 & 65 & 33 & 111 & 16 & 42 & 53 & Yes & East Asia \\
\hline $\begin{array}{l}\text { Siemianowicz } \\
{[30]}\end{array}$ & 2003 & Poland & Population-based & 146 & 48 & 60 & 38 & 44 & 6 & 20 & 18 & Yes & Caucasians \\
\hline Jeng[31] & 2003 & Taiwan & Hospital-based & 59 & 1 & 22 & 36 & 232 & 14 & 95 & 123 & Yes & East Asia \\
\hline Heijmans[32] & 2003 & Netherland & Population-based & 44 & 4 & 17 & 23 & 793 & 65 & 329 & 399 & Yes & Caucasians \\
\hline Shen[33] & 2001 & US & Population-based & 550 & 57 & 252 & 241 & 554 & 57 & 252 & 245 & Yes & Mixed \\
\hline
\end{tabular}

Table 2: Statistical heterogeneity analysis of different genetic models.

\begin{tabular}{llllll}
\hline Genetic model & Comparison & I2 & p-value & $\begin{array}{l}\text { Statistical } \\
\text { heterogeneity }\end{array}$ & Data pooling \\
\hline Dominant & TT+CT vs CC & $67.9 \%$ & $<0.01$ & Yes & Random \\
Recessive & TT vs CT+CC & $66.4 \%$ & $<0.01$ & Yes & Random \\
Homologous & TT vs CC & $72.5 \%$ & $<0.01$ & Yes & Random \\
\hline
\end{tabular}

\section{Meta-analysis}

\section{Dominant genetic model (TT+CT vs CC)}

In the dominant genetic model (TT+CT vs $\mathrm{CC})$, subjects with TT or CT alleles had an elevated risk of developing lung cancer ( $\mathrm{OR}=1.14,95 \% \mathrm{CI}: 1.01-1.28, \mathrm{p}<0.05)$ by pooling data with random effect method (Figure 2). Significant publication bias was observed in the dominant genetic model evaluated by Begg's funnel plot (Figure 3) and Egger's line regression test $(\mathrm{t}=2.44, \mathrm{p}=0.025)$.

\section{Recessive genetic model (TT vs CT+CC)}

Under the recessive genetic model (TT vs $\mathrm{CT}+\mathrm{CC}$ ), lung cancer risk was significantly increased in subjects with 


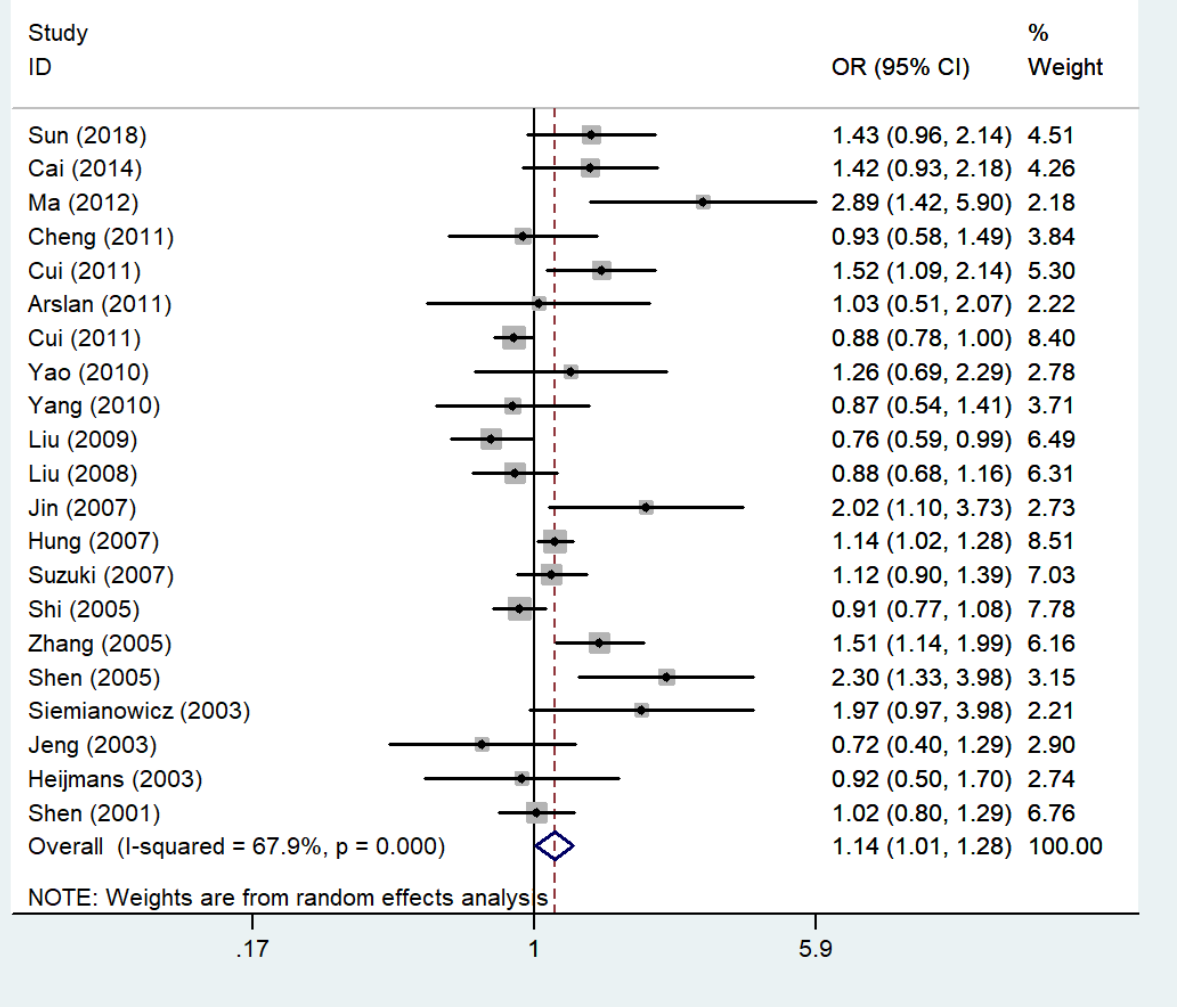

Figure 2: Forrest plot of MTHFR gene rs1801133 C>T polymorphisms and lung cancer susceptibility in the dominant genetic model (TT+CT vs CC).

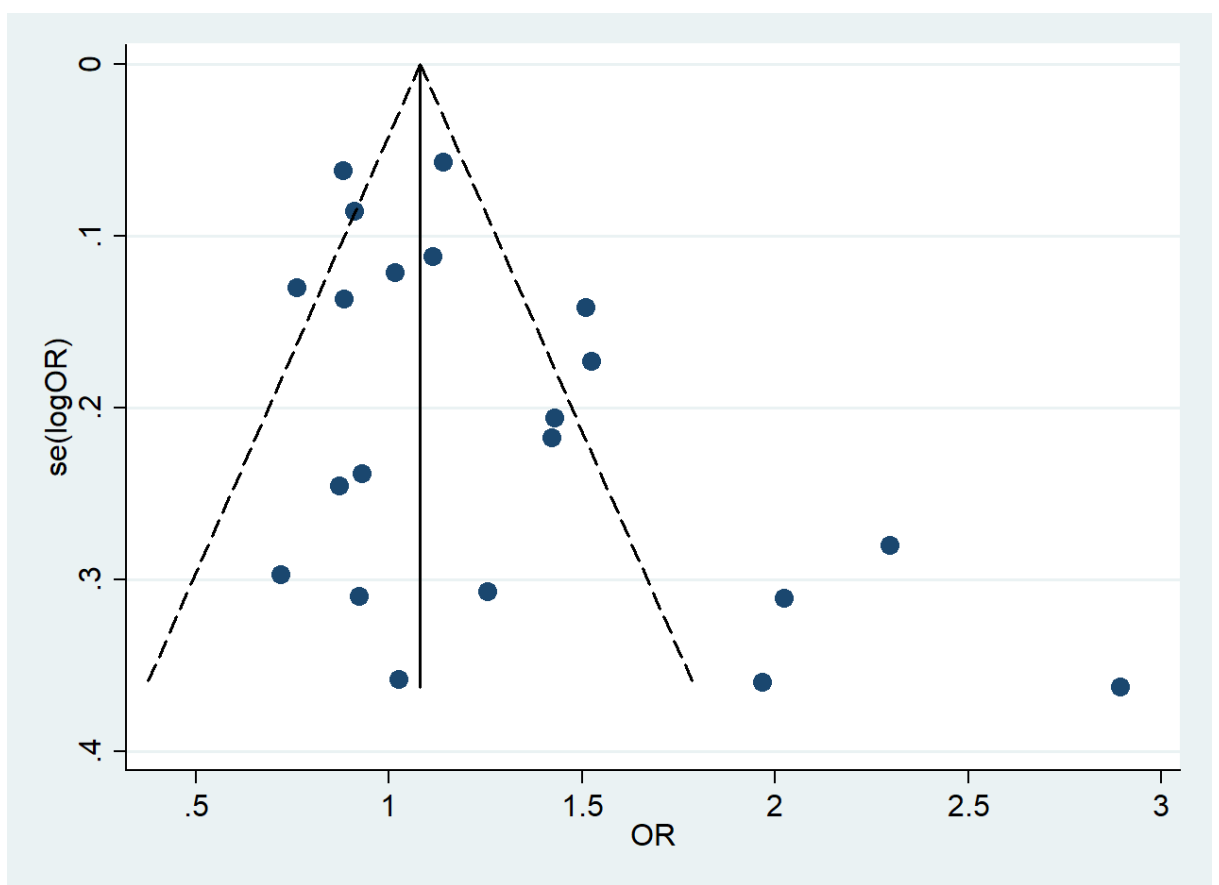

Figure 3: Funnel plot of MTHFR gene rs1801133 C>T polymorphisms and lung cancer susceptibility in the recessive genetic model (TT vs $\mathrm{CT}+\mathrm{CC}$ ). 


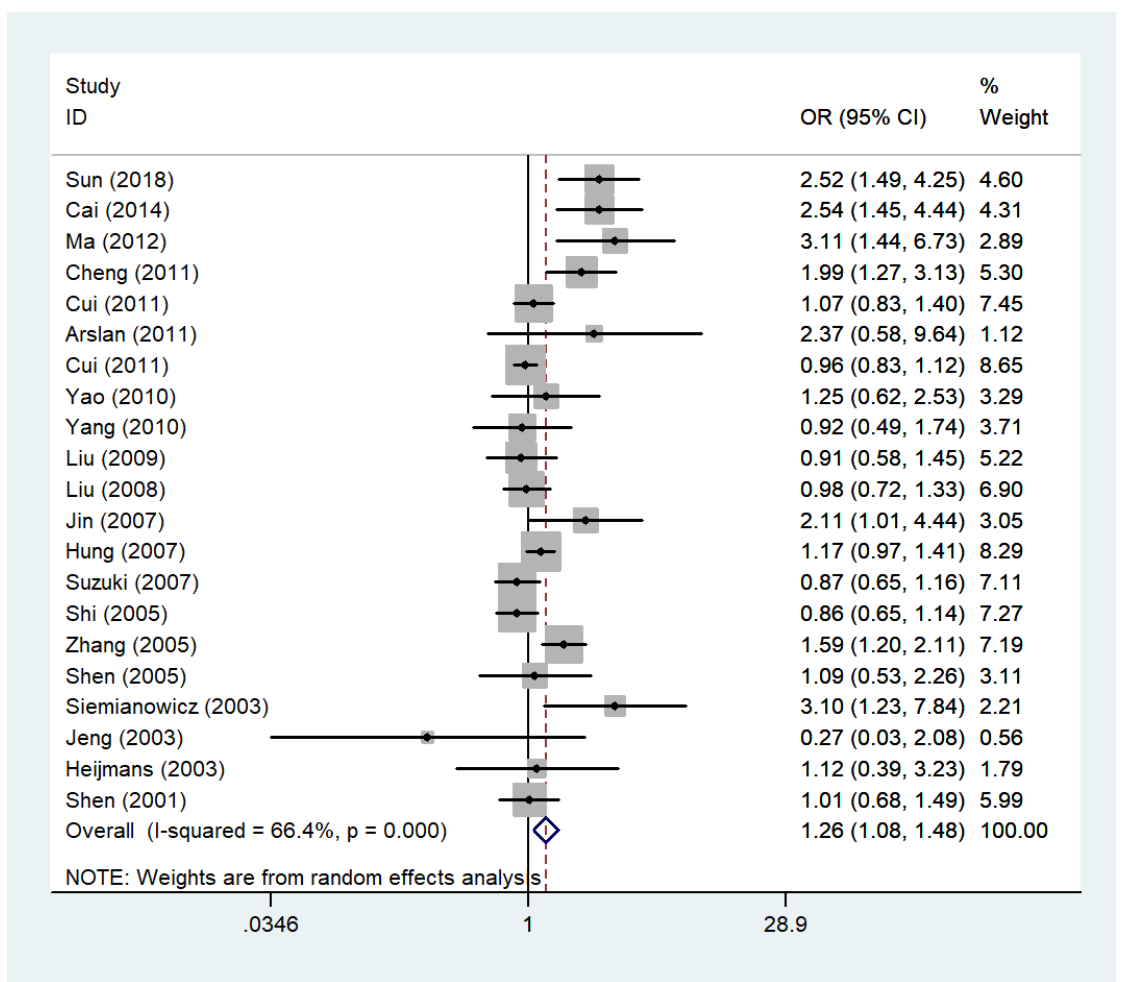

Figure 4: Forrest plot of MTHFR gene rs1801133 C>T polymorphisms and lung cancer susceptibility in the recessive genetic model (TT vs (T+CC).

TT allele compared to CC/CT (OR=1.26, 95\%CI:1.08-1.48, $\mathrm{p}<0.01$ ) in random effect model (Figure 4). Begg's funnel plot (Figure 5) and Egger's line regression test $(\mathrm{t}=2.67$, $\mathrm{p}=0.015)$ demonstrated significant publication bias.

\section{Homologous model (TT vs CC)}

In the homologous model (TT vs CC), increased lung cancer risk was found in the population with TT allele compared to $\mathrm{CC}$ with statistical difference $(\mathrm{OR}=1.36,95 \% \mathrm{CI}: 1.12-1.65$, $\mathrm{p}<0.01)$ in random effect model. Significant publication bias was determined by Begg's funnel plot (Figure 7) and Egger's line regression test $(\mathrm{t}=2.93, \mathrm{p}=0.009)$.

\section{Discussion}

In 2001, the relationship between MTHFR gene polymorphism and susceptibility to lung cancer was examined for the first time in non-Spanish Caucasians by Shen et al. [33]. It was concluded that MTHFR gene C677T (rs1801133 C>T) and A1298C polymorphisms were not associated with lung cancer. Jeng et al. [31] in 2003 also suggested that C677T locus of MTHFR gene had no risk effect on lung cancer susceptibility. Mao et al. [34] in 2008 and Boccia et al. [35] in 2009 conducted a meta-analysis of the association of MTHFR gene C677T and A1298C polymorphisms with lung cancer susceptibility. However, the correlation between MTHFR gene C677T (rs1801133 $\mathrm{C}>\mathrm{T}$ ) polymorphisms has not been identified as yet. In 2012, Hou et al [36] performed an up-date meta-analysis relevant to MTHFR gene C677T polymorphisms and lung cancer risk and found the correlation. In Hou's study, the authors found that the MTHFR 677T null genotype (T vs C) may increase NSCLC risk. However, 6 years had passed since Hou et al., reported their work and several new studies had been published. Therefore, we performed this updated meta-analysis by including the new publications relevant to MTHFR gene C677T polymorphisms and lung cancer risk in order to further elucidate the correlation.

Here, the data from 21 publications relating to MTHFR gene C677T polymorphisms and lung cancer risk were pooled. We determined $\mathrm{T}$ allele frequency in lung cancer patients was higher when compared to healthy controls in all gene expression models, indicating that populations with $\mathrm{T}$ alleles had an increased risk of developing lung cancer in all genetic models which were in accordance 


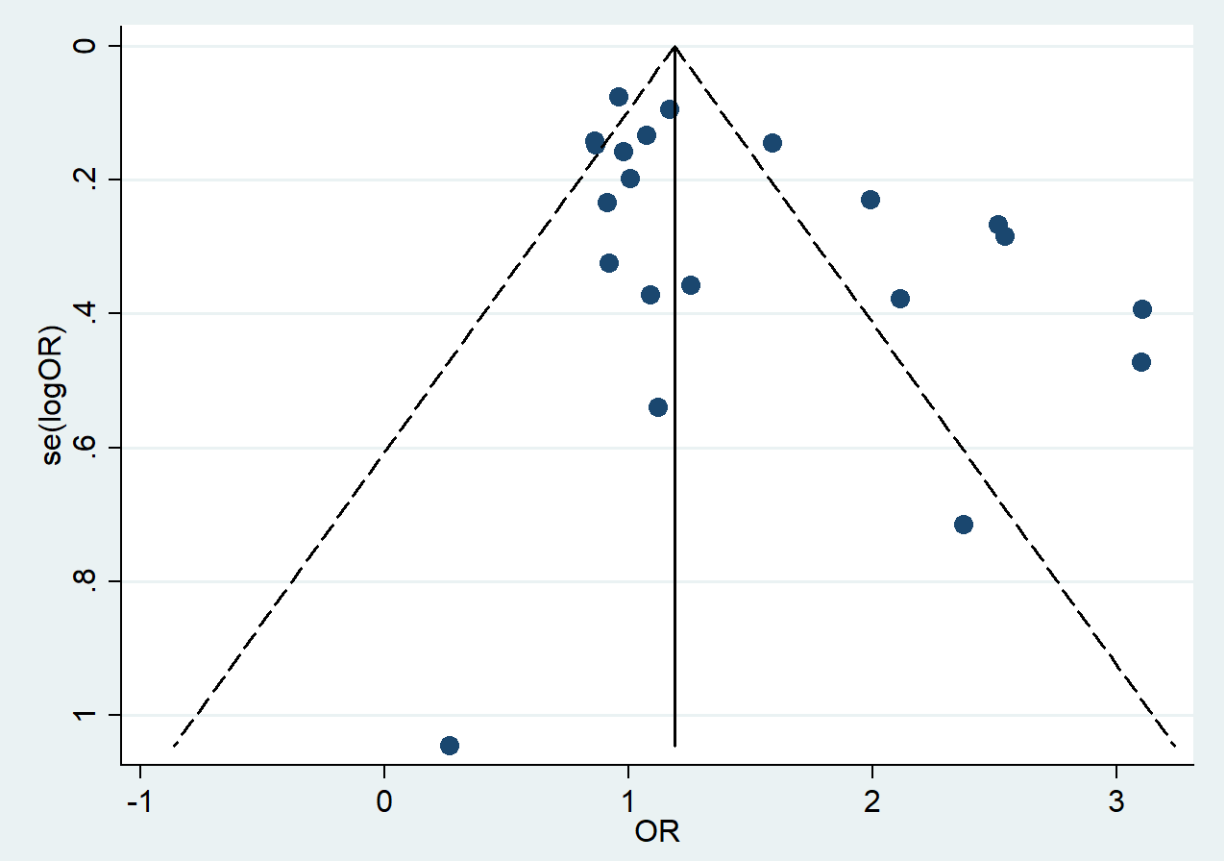

Figure 5: Funnel plot of MTHFR gene rs1801133 C>T polymorphisms and lung cancer susceptibility in the recessive genetic model (TT vs (T+CC).

\begin{tabular}{|c|c|c|}
\hline \multirow{2}{*}{$\begin{array}{l}\text { Study } \\
\text { ID }\end{array}$} & \multicolumn{2}{|r|}{$\%$} \\
\hline & OR $(95 \% \mathrm{Cl})$ & Weight \\
\hline Sun (2018) & $2.78(1.54,5.02)$ & 4.76 \\
\hline Cai (2014) & $2.80(1.50,5.24)$ & 4.50 \\
\hline Ma (2012) & $5.06(2.03,12.61)$ & 2.95 \\
\hline Cheng (2011) & $1.51(0.88,2.62)$ & 5.07 \\
\hline Cui (2011) & $1.50(1.02,2.19)$ & 6.39 \\
\hline Arslan (2011) & $2.26(0.53,9.57)$ & 1.49 \\
\hline Cui (2011) & $0.89(0.75,1.05)$ & 7.96 \\
\hline Yao (2010) & $1.40(0.63,3.13)$ & 3.47 \\
\hline Yang (2010) & $0.86(0.43,1.72)$ & 4.08 \\
\hline Liu (2009) & $0.81(0.51,1.30)$ & 5.65 \\
\hline Liu (2008) & $0.90(0.63,1.29)$ & 6.60 \\
\hline $\operatorname{Jin}(2007)$ & $3.00(1.29,6.98)$ & 3.26 \\
\hline Hung (2007) & $1.23(1.02,1.50)$ & 7.80 \\
\hline Suzuki (2007) & $0.95(0.69,1.31)$ & 6.89 \\
\hline Shi (2005) & $0.83(0.62,1.11)$ & 7.11 \\
\hline Zhang (2005) & $1.90(1.35,2.67)$ & 6.72 \\
\hline Shen (2005) & $1.81(0.81,4.03)$ & 3.47 \\
\hline Siemianowicz (2003) & $3.79(1.37,10.48)$ & 2.55 \\
\hline Jeng (2003) & $0.24(0.03,1.92)$ & 0.80 \\
\hline Heijmans (2003) & $1.07(0.36,3.19)$ & 2.30 \\
\hline Shen (2001) & $1.02(0.68,1.53)$ & 6.17 \\
\hline Overall $(\mathrm{I}$-squared $=72.5 \%, \mathrm{p}=0.000)$ & $1.36(1.12,1.65)$ & 100.00 \\
\hline NOTE: Weights are from random effects analysis & & \\
\hline $\begin{array}{c}1 \\
.031\end{array}$ & $\begin{array}{c}1 \\
32.2\end{array}$ & \\
\hline
\end{tabular}

Figure 6: Forrest plot of MTHFR gene rs1801133 C>T polymorphisms and lung cancer susceptibility in the homologous model (TT vs CC). 


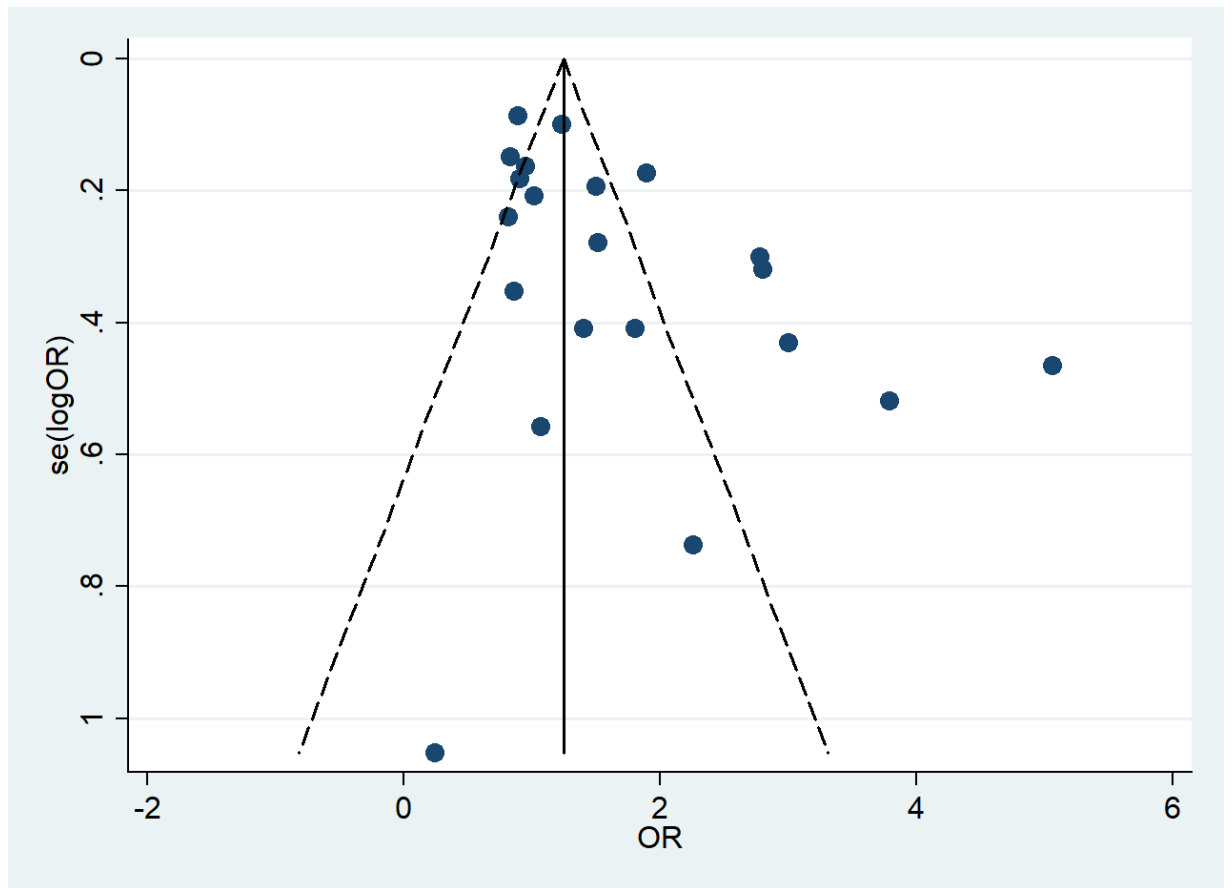

Figure 7: Funnel plot of MTHFR gene rs1801133 C>T polymorphisms and lung cancer susceptibility in the homologous model (TT vs CC)

with Hou et al., results. However, compared to Hou et al., we discussed the correlation between MTHFR gene C677T polymorphisms and lung cancer in dominant, recessive and homologous genetic models and also added 4 newly published studies which were not included in Hou et al. Although the results of the present meta-analysis were similar to Hou et al., our study provided further evidence for the potential correlation between MTHFR gene C677T polymorphisms and lung cancer susceptibility. Our work concluded that $\mathrm{T}$ allele increased the lung cancer risk compared to C. However, there are several limitations for the present study. Firstly, the statistical heterogeneity was observed in all genetic models, and the data were pooled by a random effect model. The statistical power is weaker than the fixed effect model. Secondly, significant publication bias was found in the meta-analysis which indicating studies with negative results may not be published. The heterogeneity across the included studies was potentially from two major aspects. One is from the clinical heterogeneity such as the subjects included in each study were varied in gender and ethnicity. The second clinical heterogeneity may come from the control types (hospital-based or population-based) and the third source of clinical heterogeneity may be due to the different methods of genotyping detection. The other major aspect of heterogeneity was statistical heterogeneity. The statistical heterogeneity may have arisen in describing the properties of a dataset, or several datasets. They relate to the validity of the often-convenient assumption that the statistical properties of any one part of an overall dataset are the same as any other part. In a meta-analysis which combines the data from several studies, homogeneity measures the differences or similarities between the several studies.

Methylenetetrahydrofolate reductase is a key enzyme in the folate metabolism pathway coded by the MTHFR gene which plays a key role in folate metabolism, catalyzing the irreversible conversion of 5,10-MTHF to 5-MTHF. MTHFR rs1801133 C>T can cause alanine to be replaced with valine, which reduces enzyme activity. Reduced MTHFR activity generally leads to increased 5,10MTHF for DNA synthesis and decreased 5-MTHF for DNA methylation and finally increased the cancer risk $[6,20]$.

\section{Conclusion}

Based on the present data, lung cancer susceptibility may be increased in subjects with TT or CT alleles, compared to CC alleles. However, due to the statistical heterogeneity and publication bias limitations, conclusions should be drawn with caution. We recommend more well-designed original case-control studies, cohort studies or highquality meta-analysis relevant to (MTHFR) gene rs1801133 $\mathrm{C}>\mathrm{T}$ polymorphisms and lung cancer susceptibility in order to further elucidate its correlation. 
Conflict of interest: Authors state no conflict of interest

\section{References}

1. Siegel RL, Miller KD, Jemal A. Cancer Statistics, 2017. CA Cancer J Clin 2017;67:7-30.

2. Siegel RL, Miller KD, Jemal A. Cancer Statistics, 2016. CA Cancer J Clin 2016;66:7-30.

3. Cao M, Chen W. Epidemiology of lung cancer in China. Thorac Cancer 2018.

4. Zhang X, Wu L, Xu Y, Zhang B, Wu X, Wang Y, et al. Trends in the incidence rate of lung cancer by histological type and gender in Sichuan, China, 1995-2015: A single-center retrospective study. Thorac Cancer 2018;9:532-541.

5. Ribeiro MR, Lima, Lisboa JVC, Chaves TR, Luna RCP, do Nascimento RAF, de Oliveira Y, et al Influence of the C677T Polymorphism of the MTHFR Gene on Oxidative Stress in Women With Overweight or Obesity: Response to a Dietary Folate Intervention. J Am Coll Nutr 2018:1-8.

6. Wang YC, Wu MT, Lin YJ, Tang FY, Ko HA, Chiang EP. Regulation of Folate-Mediated One-Carbon Metabolism by Glycine N-Methyltransferase (GNMT) and Methylenetetrahydrofolate Reductase (MTHFR). J Nutr Sci Vitaminol (Tokyo) 2015;61 Suppl:S148-50.

7. Cui LH, Shin MH, Kim HN, Song HR, Piao JM, Kweon SS, et al. Methylenetetrahydrofolate reductase C677T polymorphism in patients with lung cancer in a Korean population. BMC Med Genet 2011;12:28.

8. Cui LH, Yu Z, Zhang TT, Shin MH, Kim HN, Choi JS. Influence of polymorphisms in MTHFR $677 \mathrm{C} \rightarrow \mathrm{T}$, TYMS $3 R \rightarrow 2 \mathrm{R}$ and MTR $2756 \mathrm{~A} \rightarrow \mathrm{G}$ on NSCLC risk and response to platinum-based chemotherapy in advanced NSCLC. Pharmacogenomics 2011;12:797-808.

9. Larsson SC, Giovannucci E, Wolk A. Folate intake, MTHFR polymorphisms, and risk of esophageal, gastric, and pancreatic cancer: a meta-analysis. Gastroenterology 2006;131:1271-83.

10. Yang CX, Matsuo K, Ito H, Shinoda M, Hatooka S, Hirose K, et al. Gene-environment interactions between alcohol drinking and the MTHFR C677T polymorphism impact on esophageal cancer risk: results of a case-control study in Japan. Carcinogenesis 2005;26:1285-90.

11. Yeh CC, Lai CY, Chang SN, Hsieh LL, Tang R, Sung FC, et al. Polymorphisms of MTHFR C677T and A1298C associated with survival in patients with colorectal cancer treated with 5-fluorouracil-based chemotherapy. Int J Clin Oncol 2017;22:484-493.

12. Shiao SP, Yu CH. Meta-Prediction of MTHFR Gene Polymorphism Mutations and Associated Risk for Colorectal Cancer. Biol Res Nurs 2016;18:357-69.

13. Rezende LM, Marson FAL, Lima CSP, Bertuzzo CS. Can MTHFR C677T and A1298C Polymorphisms Alter the Risk and Severity of Sporadic Breast Cancer in Brazilian Women. Clin Breast Cancer 2017;17:e199-e208.

14. Gilbody S, House A. Publication bias and meta-analysis. Br J Psychiatry 1995;167:266.

15. Yun-hui S, Ting Z, Shan-shan Lg, Shu-min L, Xiao-ran X. Relationship between MTHFR gene polymorphism and lung cancer susceptibility. Journal of Clinical Pulmonary Medicine 2018;23:621-623+631.

16. Zuxun C, Feifei H, Xianping Zhang, Yanli Yang, Tao Wang, Qianyuan Li, Xuebing Ding, Shixiu Liao. Relationship between gene polymorphism of methylenetetrahydrofolate reductase enzyme and lung cancer in Henan Han population. Journal of Chinese Practical Diagnosis and Therapy 2014;28:866-868.

17. Ma QL, Li YF, Ji M, Yang KY, Wang JY, Li S, et al. Study of the association between $\mathrm{C677T}$ gene polymorphisms of methylenetetrahydrofolate reductase and susceptibility to lung cancer. Chin J Clinicians 2012;6:213-5 .

18. Cheng Z, Wang W, Song YN, Xia J, Kang Y, Dai L, et al. Association between C677T genetic polymorphisms of methylenetetrahydrofolate reductase and risk of lung cancer. Chin J Tuberc Respir Dis 2011;34:57-8 .

19. Arslan S, Karadayi S, Yildirim ME, Ozdemir O, Akkurt I. The association between methylene-tetrahydrofolate reductase gene polymorphism and lung cancer risk. Mol Biol Rep 2011;38:991-6.

20. Yao QF, Chen X, Xue JR, Luo M, Xiao L, Yang C. Relationship of polymorphisms of MTHFR gene and hypermethylation of tumor suppressor gene in lung cancers. Cancer Prev Treat 2010;37:531-4

21. Yang XX, Li FX, Yi JP, Li X, Sun JZ, Hu NY. Association between C677T genetic polymorphisms of methylenetetrahydrofolate reductase and risk of gastric cancer, colorectal cancer and lung cancer. Guangdong Med J 2010;31:2375-8 .

22. Liu CS, Tsai CW, Hsia TC, Wang RF, Liu CJ, Hang LW, et al. Interaction of methylenetetrahydrofolate reductase genotype and smoking habit in Taiwanese lung cancer patients. Cancer Genomics Proteomics 2009;6:325-9.

23. Liu H, Jin G, Wang H, Wu W, Liu Y, Qian J, et al. Association of polymorphisms in one-carbon metabolizing genes and lung cancer risk: a case-control study in Chinese population. Lung Cancer 2008;61:21-9.

24. Chuan J, Yonghui Z, Meifang P, Weidong L, Lei M, Wensheng C. Research of relationship between gene polymorphisms of methylenetetrahydrofolate reductase enzyme and lung cancer. Chinese journal of cancer prevention and treatment 2007;14:888-891.

25. Hung RJ, Hashibe M, McKay J, Gaborieau V, SzeszeniaDabrowska N, Zaridze D, et al. Folate-related genes and the risk of tobacco-related cancers in Central Europe. Carcinogenesis 2007;28:1334-40.

26. Suzuki T, Matsuo K, Hiraki A, Saito T, Sato S, Yatabe Y, et al. Impact of one-carbon metabolism-related gene polymorphisms on risk of lung cancer in Japan: a case control study. Carcinogenesis 2007;28:1718-25.

27. Shi Q, Zhang Z, Li G, Pillow PC, Hernandez LM, Spitz MR, et al. Sex differences in risk of lung cancer associated with methylene-tetrahydrofolate reductase polymorphisms. Cancer Epidemiol Biomarkers Prev 2005;14:1477-84.

28. Zhang XM, Miao XP, Tan W, Qu SN, Sun T, Zhou YF, et al. [Association between genetic polymorphisms in methylentetrahydrofolate reductase and risk of lung cancer]. Zhongguo Yi Xue Ke Xue Yuan Xue Bao 2005;27:700-3.

29. Shen M, Rothman N, Berndt SI, He X, Yeager M, Welch R, Chanock S, Caporaso N, Lan Q. Polymorphisms in folate metabolic genes and lung cancer risk in Xuan Wei, China. Lung Cancer 2005;49:299-309. 
30. Siemianowicz K, Gminski J, Garczorz W, Slabiak N, Goss M, Machalski $M$, et al. Methylenetetrahydrofolate reductase gene C677T and A1298C polymorphisms in patients with small cell and non-small cell lung cancer. Oncol Rep 2003;10:1341-4.

31. Jeng YL, Wu MH, Huang HB, Lin WY, You SL, Chu TY, et al. The methylenetetrahydrofolate reductase 677 C-->T polymorphism and lung cancer risk in a Chinese population. Anticancer Res 2003;23:5149-52.

32. Heijmans BT, Boer JM, Suchiman HE, Cornelisse CJ, Westendorp RG, Kromhout D, et al. A common variant of the methylenetetrahydrofolate reductase gene (1p36) is associated with an increased risk of cancer. Cancer Res 2003;63:1249-53.

33. Shen H, Spitz MR, Wang LE, Hong WK, Wei Q. Polymorphisms of methylene-tetrahydrofolate reductase and risk of lung cancer: a case-control study. Cancer Epidemiol Biomarkers Prev 2001;10:397-401.

34. Mao R, Fan Y, Jin Y, Bai J, Fu S. Methylenetetrahydrofolate reductase gene polymorphisms and lung cancer: a metaanalysis. J Hum Genet 2008;53:340-8.

35. Boccia S, Boffetta P, Brennan P, Ricciardi G, Gianfagna F, Matsuo K, et al. Meta-analyses of the methylenetetrahydrofolate reductase C677T and A1298C polymorphisms and risk of head and neck and lung cancer. Cancer Lett 2009;273:55-61.

36. Hou XH, Huang YM, Mi YY. Methylenetetrahydrofolate reductase gene C677T polymorphism and lung cancer: an updated metaanalysis. Asian Pac J Cancer Prev 2012;13:2025-9. 